\title{
“Sexual pleasure on equal terms”: Young women’s ideal sexual situations
}

Eva Elmerstig, RN, RM, PhD ${ }^{\text {a, b }}$, Barbro Wijma, MD, PhD ${ }^{\text {b }}$, Kerstin Sandell, $\mathrm{PhD}^{\mathrm{c}}$, Carina Berterö, RNT, $\mathrm{PhD}^{\mathrm{d}}$.

From the ${ }^{\mathrm{a}}$ Faculty of Health and Society, Malmö University, Sweden, the ${ }^{\mathrm{b}}$ Unit of Gender and Medicine, Department of Clinical and Experimental Medicine, Faculty of Health Sciences, Linköping University, Sweden, the ${ }^{\mathrm{C}}$ Department of Gender Studies, Lund University, Sweden and the ${ }^{\mathrm{d}}$ Division of Nursing Sciences, Department of Medical and Health Sciences, Faculty of Health Sciences, Linköping University, Sweden

Correspondence:

Eva Elmerstig

Faculty of Health and Society

Malmö University

SE-205 06 Malmö, Sweden

Phone: + 46406657490

Email: eva.elmerstig@mah.se

\section{Abstract}

Objective: The aim of this study was to identify young women's ideal images of sexual situations and expectations on themselves in sexual situations.

Study design: We conducted audio taped qualitative individual interviews with 14 women aged 14 to 20 years, visiting two youth centres in Sweden. Data were analysed with constant comparative analysis, the basis of grounded theory methodology.

Results: The women's ideal sexual situations in heterosexual practice were characterized by sexual pleasure on equal terms, implying that no one dominates and both partners get pleasure. There were obstacles to reaching this ideal, such as influences from social norms and demands, and experiences of the partner's "own run". An incentive to reach the ideal sexual situation was the wish to experience the well of pleasure.

Conclusions: Our research further accentuates the importance of finding ways to focus on the complexity of unequal gender norms in youth heterosexuality. A better understanding of these cognitions is essential and useful among professionals working with youths' sexual health.

Keywords: female health; psychological wellbeing; qualitative methods; sexual health; women's sexuality 


\section{Introduction}

Sexual activity among adolescents is widely accepted in Sweden. Contraceptive counselling and sexually transmitted infection (STI) testing are free of charge [1, 2] and there has also been a tradition of school education about sexuality since the mid 1950s [2]. There is an essential interest in youth sexual behaviour concerning prevention of STIs and unwanted pregnancies, and a number of Swedish studies have investigated related risk factors such as alcohol and drugs, younger age at coital debut, pornography consumption, and heterosexual gender dynamics [3-8]. Sexual dysfunctions are another important aspect of youth sexual health. Elmerstig et al. $[9,10]$ assessed young women with experience of pain during vaginal intercourse (VIC), and found that almost half of the women consulting a youth centres in Sweden during the study period reported pain during VIC [9]. In an interview study [10] aimed at understanding why young women continue to have VIC despite pain, the reasons given confirmed that the women wanted to be affirmed in their image of an ideal woman. The ideal woman's characteristics consisted of willingness to have VIC, and caring for male partner's sexual needs and satisfaction [10]. These findings raised the question: what kind of ideals of and expectations of sexual situations characterize young women without pain during VIC?

There is limited information about young women's perceptions of ideal sexual situations in spite of the fact that it is a big challenge for youngsters to develop a satisfactory sexuality. Exploring ideal sexual situations from young women's perspectives would provide helpful information.

In this study we therefore wanted to identify young women's ideal images of sexual situations and expectations on themselves in sexual situations.

\section{Methods}

In this qualitative research we were guided by Glaser's [11-13] grounded theory in identifying young women's ideal images and expectations of themselves during sexual situations, seen as social processes.

\section{Setting}

The study was carried out at two youth centres in two different cities in southern Sweden.

The services are available for youths of both sexes [1] until the age of 21. Youth centres in Sweden aim at preventing unwanted pregnancies, sexually transmitted infections (STIs), as well as psychological and social problems [1]. The staffs at the centres consist of midwives, social workers, psychologists, gynaecologists, registered nurses, and assistant nurses.

\section{Informants and sample}

Informants were 14 women aged 14 through 20 (median 18 years). All except one were born in Sweden. The women represent diverse socioeconomic groups in the cities. Two women were in their ninth year of compulsory school, eight were senior high school students attending different practical and theoretical programs, and two were university students. Two women had finished senior high school and were working. The women reported using different forms of contraception. All of them identified themselves as heterosexual, except for one woman, who identified herself as bisexual, although she had only had sexual experiences with men at the time of the interview. Additional characteristics of the sample are shown in Table I. 
Table I. Characteristics of the 14 informants in the interview study

\begin{tabular}{|c|c|c|c|}
\hline Interview & Age & $\begin{array}{l}\text { Duration of } \\
\text { present } \\
\text { relationship/ } \\
\text { Single }\end{array}$ & $\begin{array}{l}\text { Age at coital } \\
\text { debut }\end{array}$ \\
\hline 1 & 20 years & Single & 17 years \\
\hline 2 & 19 years & Single & 14 years \\
\hline 3 & 16 years & Single & 15 years \\
\hline 4 & 17 years & 2 months & 15 years \\
\hline 5 & 20 years & 3 months & 15 years \\
\hline 6 & 18 years & 1 year & 16 years \\
\hline 7 & 18 years & 1 year & 14 years \\
\hline 8 & 18 years & Single & 14 years \\
\hline 9 & 19 years & 2 years & 15 years \\
\hline 10 & 15 years & 4 months & 13 years \\
\hline 11 & 17 years & 2 months & 16 years \\
\hline 12 & 16 years & Single & 14 years \\
\hline 13 & 15 years & Single & 13 years \\
\hline 14 & 14 years & 8 months & 14 years \\
\hline
\end{tabular}

Note: Data registered at the time of the interview

\section{Data collection procedure}

The study was approved by the regional ethical review board, Linköping University, Sweden (Record No: 03-522).

Young women attending the two youth centres were invited to participate in qualitative interviews after having received written and oral information about the study. Eligibility criteria were: women less than 21 years of age, who spoke and understood Swedish, had had VIC during the previous six months, and had never experienced pain during VIC. Purposive sampling ensured a heterogeneous sample of ages. Potential informants were contacted by the first author (EE) by telephone; if they agreed to participate an appointment was made. Of those 37 women who initially agreed to participate, two no longer wished to participate when contacted, and another three women's telephone calls were disconnected.

Fourteen qualitative interviews were conducted by EE at the youth centres. After obtaining informed consent, EE completed a demographic survey with the informants assessing age, coital debut age, school/work, ethnicity, contraception method, single/partner, and if they experienced themselves as hetero-, homo-, or bisexual.

The interviews followed an interview guide constructed for the study $[14,15]$ consisting of open-ended questions such as, "Can you tell me what a normal sexual situation is for you?", "What is good sex for you?", and "Do you feel expectations about how to act as a woman in a sexual situation?" Based on the women's responses, subsequent exploring questions were posed.

Each woman participated in one individual, audio taped interview, lasting from 30 to 90 minutes. Interviews were transcribed verbatim. Tapes were identified only by coded numbers. Sampling continued until theoretical saturation was reached (i.e., the point when additional data do not substantially contribute to the categories) [11, 12] which was after 11 interviews had been analyzed. Analysis of three additional interviews confirmed saturation, and no further interviews were conducted after that. The remaining 18 women were consequently not interviewed. 


\section{Data analysis}

Data were analysed inductively using constant comparative analysis: a systematic process of coding and comparing raw data, the basis for grounded theory, with the aim of generating theory grounded in the data [11-13]. The analysis leads to a description of concepts to explain psychosocial processes $[11,15]$.

Each audio taped interview was compared with the transcript to assure transcription accuracy. Starting with the first interview, the transcripts were examined line by line to identify meaningful units of text, consisting of words, phrases, or concepts used by the informants. For each interview these meaningful units were coded consecutively, generating substantive codes, labelled with names from the data $[12,13]$. The process of "constant comparison" of the data means that each substantive code is compared with other substantive codes from the same and other interviews. During this process patterns and similarities appeared, and categories at a higher abstraction level emerged. Validation of the relationships between the developed abstract categories continued during the constantly comparative analysis of substantive codes and categories. Memos [16] derived from the interviews and all the way through the analyses, were used to create an understanding of categories relation to each other. As we repeatedly examined the categories a relational statement was identified; the core category, which could explain young women's ideal images and expectations of themselves in sexual situations. The core category is a theoretical construct, answering the question "what is actually happening in the data?" [12]

To ensure the trustworthiness of the research process and findings [17], EE and the last author (CB) discussed the data and the analysis and resolved any differences in their interpretations of the results.

\section{Results}

The informants shared the definition of a normal heterosexual situation as VIC: for some of the women a normal sexual situation also included oral sex.

The core category "Sexual pleasure on equal terms" and three categories: "Social norms and demands," "Partner's own run" and "A well of pleasure" emerged during the analysis. Partner's own run is described as a partner merely focused on himself, and a well of pleasure illustrates a pleasure full of nuances. The results section first presents the core category and then describes the categories. All categories are at an abstract level, while the quotations are at a descriptive level.

\section{Core category: Sexual pleasure on equal terms}

The analysis revealed that the women's ideal sexual situations are characterized by "sexual pleasure on equal terms". Social norms and demands, perceived within themselves and/or from peer groups, and experiences of partner's “own run”, create difficulties reaching the ideal. The women's experience of the well of pleasure enables them to strive for the ideal sexual situation, in spite of the influencing factors: social norms and demands and partner's "own run". It is easier to reach the ideal sexual situation in a relationship that has lasted for a while, than in one that just started, or in a one-night stand.

The core variable "sexual pleasure on equal terms" is defined as a sexual situation where the man and the woman are on an equal footing with each other. They satisfy each other and they attain mutual sexual pleasure. It is important for both to be able to give and take, and to agree on actions that give both pleasure. Each must listen to what the other wants and does not 
want, and be aware of the partner's presence. No one should dominate, and the atmosphere permits saying no if something is not pleasurable.

Social norms and demands, mediated via various forms of media, partners and peers, have a negative impact on women's chances to reach this ideal sexual situation. The image of what a woman should be like is shown in everyday commercial situations and films. A woman is often described as an object with no will of her own, which enables others to do what they want with her. The conception of a woman's subordination influences both the informant's and her partner's sexual life, and also the peer context. A woman's awareness and critiques of social norms and demands make it theoretically possible, yet difficult, for them to resist that influence.

"Sexual pleasure on equal terms" is also negatively dependent on experiences of the male partner's "own run", based on their own experiences or on what they learnt from peer groups. The image of partners going for their "own run" is reinforced by experiences of partners who were totally focused on themselves and their own pleasure in sexual situations, without taking notice of the female partners' wishes or needs. The partner interacts with a visible body, but does not see the rest of the woman.

An incentive to reach the ideal sexual situation is the wish to experience the well of pleasure. To reach sexual pleasure through caressing and physical closeness in a situation characterized by confidence and mutuality, during the most intimate stages of a sexual situation, leads to a desire to experience it again.

\section{Table II}

Quotation from the Core category: Sexual pleasure on equal terms

\section{Sexual pleasure on equal terms}

"Both should feel pleasure...that is very important...both should feel comfortable// It should be equal pleasure for both...If I am not willing to do all things, he should not force me, he should have understanding for that...in the same way as I should have understanding if he is not willing to do everything...it should be equal for both."

(Interview 4)

\section{Social norms and demands}

The women are bombarded with expectations of what a woman should be like, i.e., the unequal gendered societal norms of the obliging woman who is always willing to satisfy everyone. The women described commercial events, films and weekly magazines as influential, where women are consistently depicted as devalued objects. The social norms and demands of being at a disadvantage in the society are also reflected in the women's position in the sexual situation, where they tend to put more focus on the importance of men's sexual pleasure and orgasm than on their own. They feel an indirect pressure from peer groups and partners to do this in order to fit in.

The young women described problems from pornography supplying wrong signals to young women and men, at an age when they begin to get interested in sexual activities and are easy to influence. Pornography turns out to be the only source concretely showing sexual 
situations, but strongly conveys unequal gender norms: men as macho, always knowing what they want, and women as passive, doing whatever men want. Such influence enhances the women's subordination. Even if the women feel like strong women as individuals and hope not to be easily influenced, they still reported awareness of the impact of unequal images and norms. The women experienced a conflict in wanting to resist this impact, while at the same time wanting to feel appreciated --- by satisfying others.

Their ultimate, ideal sexual situations consist of "sexual pleasure on equal terms" where all influence from unequal gendered social norms and demands is absent.

\section{Partner's “own run”}

Images and attitudes about the partner's “own run” are central for these women, based on their own experiences and/or what they have heard from peer groups and friends.

The women described bad sex as being with a male partner whose attitude is that the woman's task is to satisfy the man; and when the partner's "own run" is over, the sexual act is over --leaving no room for the woman's pleasure. The women feel that some men take advantage of women's subordinated position in diverse contexts in the society. The women have had experiences with selfish partners that just push on and get cross if the woman does not want to do everything for them. They feel an underlying pressure to fit the image of how a woman should be: to undervalue her own pleasure and just focus on the partner's pleasure. To avoid nagging about some sexual activities they do not like, like anal sex, they sometimes finally go through with it because they want to oblige the partner.

Even if the women know of partners not showing that attitude, they still have an implicit knowledge about the expectations a partner is likely to have. Such presumed partner expectations have a greater impact in the beginning of a relationship and/or in a one-night stand. As the conception about the partner's "own run" is prevalent, it is difficult for the women to ignore that and only focus on "sexual pleasure on equal terms".

\section{A well of pleasure}

The women's desire to reach the well of pleasure makes them strive for the ideal sexual situation. The well of pleasure consists of several parts in the sexual situation. When the women can relax and feel confident with their partners, they are able to feel pleasure through physical closeness and warmth. They enjoy the sensual pleasure of being touched and feel it pleasurable to be themselves without the demand of fulfilling someone's expectations. Perceiving pleasure together is the most intimate situation two people could experience and is the most attractive. The women express that the experience of pleasure gives a feeling of happiness and that having sex should be fun. When both partners are sexually excited, the women feel a desire for exploring the partner and to be explored. The experience of pleasure is the incentive to long for experiencing such a sexual situation again. 


\section{Table III \\ Quotations from the categories Social norms and demands, Partner's “own run” and $A$ well of pleasure.}

\section{Social norms and demands \\ "...from porn movies and everything, that you should be in a special way as a girl...that you are inferior in a way// That it is the woman's task to satisfy the man...and the woman gets nothing back... in a way.../It is that image you get in the society...it is impressed in one's mind...it is like that on the whole, the male-dominated society is everywhere... and that image is there also, in the society... the whole world...everywhere...on companies, in family life, everywhere...it is an image you learn from when you are young...you take part in those roles, that a man is more worth...than a woman" \\ (Interview 5)}

\section{Partner's “own run”}

"When you feel as if being used in a way...you feel that you are not allowed to bring anything by yourself, you just became, yes a hole...you are just lying there and don't supply anything by yourself...the guy just doing his own run...when you feel as cheap and used... Yes, you have no say or...he doesn't care...you could have a plastic bag over the head and he won't even notice it, he just doesn't think about who he has sex with...you feel as being used...You don't do resistance, or you don't say no, but still it feels as the guy doesn't care with whom he has sex, it's just someone he can have sex with, you happen to be that girl..."

(Interview 8)

\section{A well of pleasure}

"The sexual thing stands above...because it becomes even more...it is sort of both caress and closeness, and everything, it becomes so greatly...closeness...you strike each other gently, he is inside you// someone comes inside you...it is almost like someone listening to yоu...”

(Interview 14)

\section{Discussion}

In the present qualitative study, "sexual pleasure on equal terms" was the young woman's ideal (hetero) sexual situation. This ideal state in heterosexual practice consists of both partners feeling sexual pleasure, no one dominating, and the freedom to say no if something during the sexual situation becomes not pleasurable.

The results demonstrate that diverse social processes had an impact on the women's attempts to reach the ideal sexual situation: "sexual pleasure on equal terms".

Firstly, the women were under the negative influences of social norms and demands. The informants described an image of how a woman should be: obliging and always willing to satisfy everyone around her. The impact of the notion of the subordinated woman, appearing 
in the women's sexual situation, was mediated by various forms of media, but also came from the partner, and peers. Effects of unequal societal notions of gender have been seen influencing negatively in other research assessing youth sexuality [6-8, 18, 19]. Christianson et al $[8,19]$ found similar gender expectations in her studies of STIs in youths: both young women and men found that women should be the caring and responsible party $[8,19]$. The men's irresponsibility was considered as masculine [19]. In another study Ekstrand et al. showed that young women had the perception that they were more responsible than men for avoiding pregnancy [7]. The opposition between a wish for pleasure conveyed in the notion of an ideal sexual situation, and societal norms of unequal gender expectations, was felt by the women in our study as an individual conflict, inside them. Being critically aware of social norms and demands, they wanted to both resist their impact and stick to their wish for sexual pleasure on equal terms. Still they needed to feel appreciated as women and partners in their cultural context. For professionals working with psychosomatic gynecology/medical practice it is of clinical value to be aware of this conflict, as physicians, psychologists, social workers and midwives working with young women have the possibility to support women to resist unequal societal norms and demands, and aim for sexual pleasure on equal terms.

The conflicting feeling that the women in our study expressed, affects their chances of experiencing sexual pleasure as they cannot focus completely on the sexual interaction and their desire and excitement, while they are at the same time busy trying to perform according to gender standards. By these mechanisms, the dynamics in perceived unequal gender expectations may have an impact on diverse areas related to gynecology as e.g. pain during VIC, sexual response cycle encompassing problems with sexual desire and possibility to achieve orgasm.

Secondly, accepting the partner's "own run" was an obvious obstacle to reach "sexual pleasure on equal terms". The notion of a partner being selfish, taking no notice of the woman, was based on the women's own experiences and/or on what they had heard from peer groups and friends.

Holland et al. [18] revealed a view of hegemonic masculinity norms in young people's sexual lives, where social processes construct males' sexual needs and women's responsibility for their satisfaction [18]. Although we did not focus on partner's behaviour in this study, the women clearly demonstrated the influence of ideals of masculinity on their sexual situations.

Young men probably get masculinity affirmation in male-male relations [20] when telling sexual stories about their "own run". It is understandable that women have to struggle to resist both their own demands relating to femininity ideals and their partner's masculinity ideals. Other studies have argued that these unequal gender norms are probably stronger in the beginning of a relationship $[18,21]$. This corresponds to our findings, where the women expected to take a subordinate role in the beginning of a relationship, or in a one-night stand. Thirdly, although the women were influenced by social norms and demands and the acceptance of the partner's "own run" they demonstrated the desire to experience pleasure. Having experienced an ideal sexual situation of "sexual pleasure on equal terms" created a desire in the women to relive those experiences.

The women in our study are probably not as vulnerable in this situation as if they had had pain and/or discomfort during VIC [10]. They felt the pressure of unequal social norms and demands, and the presence of the partner's "own run”, but also a well of pleasure, which increases their chances of resisting the negative societal influences. When women are in a vulnerable situation, such as having pain and discomfort during VIC, research shows that conventional feminine stereotypes become more dominant [10]. If they continue to have VIC despite pain, the pleasure disappears, and the sexual situation becomes firmly associated with negative emotions, which in the end creates a negative cognitive schema with decreased sexual desire [10]. 
The qualitative method was chosen to obtain rich and detailed descriptions of young women's social interactions in sexual situations. Capturing experience-based information is often easier through qualitative methods than quantitative ones. To address the research question, we chose grounded theory because of its ability in developing theories concerning psychosocial processes $[11,15]$. Although an in-depth qualitative interview study has the potential for gathering information in great detail, there are also limitations. The selected sample comes from a specific context that hampers generalizability. However, findings in qualitative studies do not aim for generalizability in a traditional way, to larger populations [16]; instead, the findings should be transferable to similar contexts [22]. There is a lack of information about which women do not visit youth centres in Sweden. However, one report showed that $95 \%$ of young women born in 1976 attended a youth centre at least once during the age period 17 to 20 years [1, 2]. The informants in our study came from two youth centres, representing two different parts of Sweden, but there was no ethnic diversity among the informants. Despite limitations, however, the study provides important insights into young women's sexual conditions. The women's experiences are noteworthy in a country which is striving for gender equality. It raises the question how young women's experiences are, in countries less equal? Wider verification in further qualitative studies with ethnic diversity, as well as larger quantitative studies, would provide more information on this subject.

In conclusion, the findings contribute to the understanding of young women's ideal (hetero) sexual situations and which factors hamper their chances of reaching them.

Our research reinforces the importance of focusing on the complexity of unequal gender expectations and their influence on young people's heterosexuality. A better understanding of these interactions is essential for professionals working with youths. Of special note is the importance to promote sexual and reproductive health by pointing out the influence of stereotyped gender norms and initiating critical reflexions on how they can be challenged.

Further research should explore young heterosexual men's ideal sexual situations and expectations. In what way do internalized hegemonic masculinity norms affect young men's sexual experiences and, in addition, indirectly affect young women's sexual health?

A worthy direction for future research would be to examine the impact of femininity and masculinity norms in youth's sexual pleasure and satisfaction.

\section{Acknowledgments}

We are most grateful to the women participating in this study.

\section{Declaration of interest}

This study was supported by The Swedish Research Council, record No: 521-3003-5150 and The Medical Research Council of Southeast Sweden (FORSS).

There are no financial or other relationships that might lead to conflict of interest. The authors alone are responsible for the content and writing of the paper. 


\section{References}

1. FSUM. Policyprogramme for Sweden's Youth Centres [Internet]. [cited 2012 Apr 11]; Available from http://www.fsum.org/?page_id=37

2. Danielsson M, Rogala C, Sundström K. Teenage Sexual and Reproductive Behavior in Developed Countries: Country Report for Sweden [Internet]. New York: Alan Guttmacher. Occasional Report, No.7. 2001; [cited 2012 Apr 11]; Available from http://www.guttmacher.org/pubs/summaries/sweden_teen.pdf

3. Ekstrand M, Tydén T, Darj E, Larsson M. Preventing pregnancy: a girls' issue. Seventeen-year-old Swedish boys' perceptions on abortion, reproduction and use of contraception. Eur J Contracept Reprod Health Care 2007; 12:111-8.

4. Haggstrom-Nordin E, Hanson U, Tydén T. Associations between pornography consumption and sexual practices among adolescents in Sweden. Int J STD AIDS 2005; 16:102-7.

5. Swedin CG, Åkerman I, \& Priebe, G. Frequent users of pornography. A population based epidemiological study of Swedish male adolescents. Journal of Adolescence 2011; 34: 779-788.

6. Christianson M, Lalos A, Westman G, Johansson E. "Eyes Wide Shut"--sexuality and risk in HIV-positive youth in Sweden: a qualitative study. Scand J Public Health 2007; 35: $55-61$.

7. Ekstrand M, Larsson M, von Essen L, Tydén T. Swedish teenager perceptions of teenage pregnancy, abortion, sexual behavior, and contraceptive habits--a focus group study among 17-year-old female high-school students. Acta Obstet Gynecol Scand 2005; 84: 980-6.

8. Christianson M, Johansson E, Emmelin M, et al. "One-night stands" - risky trips between lust and trust: qualitative interviews with Chlamydia trachomatis infected youth in North Sweden. Scand J Public Health 2003; 31: 44-50.

9. Elmerstig E, Wijma B, Swahnberg K. Young Swedish women's experience of pain and discomfort during sexual intercourse. Acta Obstet Gynecol Scand 2009; 88: 98103.

10. Elmerstig E, Wijma B, Bertero C. Why do young women continue to have sexual intercourse despite pain? J Adolesc Health 2008; 43: 357-63.

11. Glaser BG, Strauss AL. The Discovery of Grounded Theory: Strategies for Qualitative Research. 1967, Mill Valley, California: Sociology Press.

12. Glaser BG, Theoretical Sensitivity: Advances in the Methodology of Grounded Theory. 1978, Mill Valley, California: Sociology Press.

13. Schreiber RS, Stern PN. Using grounded theory in nursing., ed. S.P. In Schreiber RS, eds. 2001, New York: Springer Publishing Company, Inc.

14. Patton MQ. Qualitative evaluation and research methods, ed. n. edn. 1990, Newsbury Park, California: Sage publications, Inc.

15. Streubert HJ, Carpenter DR. Qualitative Research in Nursing. Advancing the Humanistic Imperative. 2nd ed. 1999, Philadelphia: Lippincott.

16. Denzin NK, Lincoln YS, Strategies of Qualitative Inquiry. 2nd. ed. 2003, Thousand Oaks, California: Sage Publications, Inc.

17. Denzin NK, Lincoln YS. Handbook of Qualitative Research. 1994, Thousand Oaks, California.: Sage Publications, Inc.

18. Holland J, Ramazanoglu C, Sharpe S, et al., The Male in the Head- Young people, heterosexuality and power. 2004, London: the Tufnell Press. 
19. Christianson M, Lalos A, Johansson EE. Concepts of risk among young Swedes tested negative for HIV in primary care. Scand J Prim Health Care 2007; 25: 38-43.

20. Flood M, Men, Sex, and Homosociality. How Bonds between Men Shape Their Sexual Relations with Women. Men and Masculinities, 2008, 10(3): 339-359.

21. Impett EA, Schooler D, Tolman DL. To Be Seen and Not Heard: Femininity Ideology and Adolescent Girls' Sexual Health. Arch Sex Behav 2006; 35; 131-44

22. Patton MQ. Qualitative Research \& Evaluation Methods. 3rd. ed. 2002, Thousand Oaks, California: Sage Publications.

\section{Current knowledge on this subject}

In heterosexual relationships, the conventional gender norms differ between the sexes and influence sexuality, especially during the sensitive transition period from childhood to adolescence.

Several studies have examined gender structures within the context of issues as safer sex, and have found that both masculinity and femininity norms and ideals affect the sexuality of many young people.

Current research about healthy young women's perceptions of ideal sexual situations is limited, in spite of the fact that it is a big challenge for young people to develop a satisfactory sexuality.

\section{What this study adds}

The young women's ideal (hetero) sexual situation in this study consisted of "sexual pleasure on equal terms" implying that no one dominates, and the man and the woman satisfy each other, and both attain sexual pleasure.

The study reveals how influences of the social norm of women being in a subordinated position affect young women's ability to reach the ideal (hetero) sexual situation "sexual pleasure on equal terms".

Our study reinforces the importance of finding ways to focus on the complexity of unequal gender norms and expectations and their influences on youth heterosexuality. 